\title{
EVALUATION OF PREOPERATIVE DIAGNOSTIC ACCURACY OF MODIFIED ALVARADO SCORING SYSTEM IN ACUTE APPENDICITIS
}

\author{
Yamuna V. S1, Jagannath², Kirankumar K. Mㄴ, Ved Prakash Ranjan', Karthik ${ }^{5}$
}

1 Junior Resident, Department of General Surgery, Sri Siddhartha Medical College, Tumkur, Karnataka, India.

2 Professor, Department of General Surgery, Sri Siddhartha Medical College, Tumkur, Karnataka, India.

3 Professor, Department of General Surgery, Sri Siddhartha Medical College, Tumkur, Karnataka, India.

4Junior Resident, Department of General Surgery, Sri Siddhartha Medical College, Tumkur, Karnataka, India.

5Junior Resident, Department of General Surgery, Sri Siddhartha Medical College, Tumkur, Karnataka, India.

\section{ABSTRACT}

\section{BACKGROUND}

The Modified Alvarado Scoring System (MASS) has been shown to be easy, simple and cheap diagnostic tool for supporting the diagnosis of acute appendicitis. However, its application and usefulness has not been evaluated in the current study settings in the diagnosis of acute appendicitis. Hence, this study was conducted.

Objectives-

1. To evaluate the specificity and sensitivity of Modified Alvarado Scoring System in the diagnosis of Acute Appendicitis.

2. To assess the rate of negative laparotomies.

\section{MATERIALS AND METHODS}

A cross-sectional study was conducted for a period of 18 months among 107 patients presenting at the surgery OPD, Sri Siddhartha Medical College Hospital and Research Centre, Tumkur, with complaints of pain in right iliac fossa with suspected features of acute appendicitis. The informed consent was taken. After considering the inclusion and exclusion criteriae, study subjects were categorised based on modified Alvarado scoring system. The subjects with $\geq 7$ were made to undergo appendicectomy and those with score $<7$ were re-scored after conservative management. The pre-operative diagnostic accuracy was evaluated.

\section{RESULTS}

The mean age of the study participants was $26.54 \pm 10.46$ yrs. and majority were males. Most frequent complaint was nausea and/or vomiting. The sensitivity, specificity, positive (PPV) and negative predictive values (NPV) and diagnostic accuracy were 97.4\%, 79.3\%, 92.7\%, 92.0\%, 92.5\% respectively. Negative appendicectomy rate was $7.3 \%$.

\section{CONCLUSION}

MASS score of $\geq 7$ is found to be having high sensitivity, PPV, NPV and good specificity, hence can be used as diagnostic indicator of acute appendicitis in the low resource setting.

\section{KEY WORDS}

Appendicectomy, Modified Alvarado Scoring, Negative Laparotomies.

HOW TO CITE THIS ARTICLE: Yamuna VS, Jagannath, Kirankumar KM et al. Evaluation of preoperative diagnostic accuracy of modified Alvarado scoring system in acute appendicitis. J. Evolution Med. Dent. Sci. 2018;7(28):3253-3256, DOI: $10.14260 /$ jemds/2018/731

\section{BACKGROUND}

Acute appendicitis, a most common surgical emergency requiring surgical intervention worldwide. ${ }^{1,2}$ Its incidence rate being $0.12 \%$ is highest among teenagers and young adults. ${ }^{3}$ The accurate diagnosis of acute appendicitis in preoperative period remains an inscrutable challenge. ${ }^{4}$ Commonly used diagnostic aids for appendicitis are CECT abdomen, laparoscopy, diagnostic scores and ultrasonography and if surgical decision to perform an appendicectomy is based only on the patient's symptoms and signs, the chances of resecting normal appendices range from $15 \%$ to $30 \%$ cases. $5,6,7$

'Financial or Other Competing Interest': None.

Submission 05-03-2018, Peer Review 17-03-2018,

Acceptance 19-03-2018, Published 09-07-2018.

Corresponding Author:

Yamuna V.S

Junior Resident,

Department of General Surgery,

Sri Siddhartha Medical College, Tumkur, Karnataka.

E-mail:vsyam69@gmail.com

DOI: $10.14260 /$ jemds $/ 2018 / 731$

\section{(c) $(1)$}

It has been stated that ultrasonography is one of the preoperative evaluation technique, which dramatically reduces the number of appendicectomies in patients without appendicitis. $^{8}$

Alvarado developed a scoring system for early diagnosis of acute appendicitis that was developed in 1986. Based on clinical signs, symptoms and differential leucocyte count with left shift of neutrophil maturation, it yielded a score of $10 .^{2}$

Kalan $\mathrm{M}$ et al produced Modified Alvarado Score with 9 point scoring system that helps in increasing accuracy of preoperative diagnosis and thus reducing negative appendicectomy rate. Score of 7 or more has been recommended for surgery.9,10 The MASS has been shown to be easy, simple and cheap diagnostic tool for supporting the diagnosis of acute appendicitis, especially for junior surgeons. ${ }^{11,12}$ However, its application and usefulness in the diagnosis of acute appendicitis has not been evaluated in the current study settings and hence this study was conducted with the following objectives: 1) To evaluate the specificity and sensitivity of Modified Alvarado Scoring System in the diagnosis of Acute Appendicitis and 2) To assess the rate of negative laparotomies. 


\section{MATERIALS AND METHODS}

A cross-sectional study was conducted at the outpatient Department of Surgery, Sri Siddhartha Medical College Hospital and Research Centre, Tumkur district, Karnataka for a period of 18 Months (October $1^{\text {st }} 2015$ to March 31st 2017) among the patients presenting at the surgery OPD with complaints of pain in right iliac fossa with suspected features of acute appendicitis. Considering an average of prevalence of acute appendicitis as per other studies as $89.3 \%$ with $95 \%$ confidence interval and permissible error (L) in the estimate of 'p' as $10 \%$, total sample size of 96.94 was calculated using the formula $\mathrm{n}=\mathrm{z}^{2}\left(\mathrm{pq} / \mathrm{L}^{2}\right)$, where, $\mathrm{z}=1.96$ at $95 \%$ confidence interval, $\mathrm{p}=$ estimated prevalence $(89.3 \%), \mathrm{q}=100-\mathrm{p}(10.7 \%)$ and $\mathrm{L}=$ permissible error $(10 \%$ of $\mathrm{p})$. The total sample size (n) of $96.94 \approx 97$ and adding a $10 \%$ non-response to $\mathrm{n}$, $97+9.7=106.7,107$ patients were considered for the study. The patients provisionally diagnosed as having acute appendicitis and willing to give consent for the study were included for the study and patients with appendicitis in pregnancy with appendicular mass or abscess, on chemotherapy and radiotherapy and immuno-compromised patients were excluded from the study. The ethical approval was taken from the IEC Committee of Sri Siddhartha Medical College Hospital and Research Centre, Tumkur district, Karnataka. After obtaining the written informed consent from patients, a detailed clinical history was taken from patients as per the proforma. All the patients were examined clinically and were subjected to routine blood investigations (complete haemogram, bleeding time, clotting time, urine sugar, albumin and microscopy, blood sugar levels, blood urea, serum creatinine), chest x-ray, ECG and ultrasonography of abdomen and pelvis. The study subjects were categorised based on modified Alvarado score. Those with 1 - 3 were sent back with oral antibiotics and were asked to report back if the symptoms persisted even after the course of antibiotics. Those who were categorised in 4 - 6 were admitted and given parenteral antibiotics and were reassessed for next 24 hours for revision of scoring. If score became $\geq 7$ or their clinical condition was highly suspicious of acute appendicitis, they were subjected for appendicectomy. Those who were categorised under 7 - 9 were taken for surgery. For those with modified Alvarado scoring of $\geq 7$ and $<7$, the positives were considered based on histopathological confirmation and for considering negatives HPE confirmation was considered for patients with score of $\geq 7$ and USG was considered for patients with $<7$, as everybody in the study were not subjected to surgery. Following the consideration of positives and negatives, the evaluation of modified Alvarado scoring was done based on sensitivity, specificity, positive predictive value, negative predictive values and diagnostic accuracies. Negative laparotomies were assessed only for those with score of $\geq 7$.

\section{Statistical Analysis}

The collected data were entered into an Excel sheet. The data were expressed in means and proportions, and presented in the form of tables and graphs wherever necessary. The mean and standard deviation of age, median and interquartile range of modified Alvarado scores were calculated. Sensitivity, specificity, positive predictive value and negative predictive values were calculated by using the formulae: Sensitivity $=$ [True Positives/ (True Positives + False
Negatives) ${ }^{*} 100 ; \quad$ Specificity $=\quad[$ True $\quad$ Negatives $/$ True Negatives + False Positives) $]^{* 100}$; Positive predictive value $=$ [True Positives/(True Positives + False Positives)]*100; Negative predictive value $=[$ True Negatives $/$ True Negatives + False Negatives) ${ }^{*} 100$; Diagnostic Accuracy= [(True Positives + True Negatives)/Total number of patients]*100; Negative Laparotomy $=[$ False Positive $/$ False Positive + True Positive)]*100. The analysis was done using standard statistical package. The association between the scores and other standard evaluation techniques was assessed using Fisher's exact test. A P-value of $<0.05$ was taken as statistically significant.

\section{RESULTS}

The mean age of the study participants was $26.54 \pm 10.46$ yrs. Majority, i.e. $45.8 \%$ were in the age group of 21 - 30 yrs. Males predominated $(67.3 \%)$ the study. The most frequent complaint was nausea and/or vomiting (86.7\%) followed by loss of appetite and migration of pain. $95.2 \%$ had right iliac fossa tenderness followed by $79.0 \%$ had rebound tenderness. $80.0 \%$ had elevated temperature and $49.5 \%$ had leucocytosis. $76.6 \%$ had a modified Alvarado score of $\geq 7$ and rest belonged to $<7$, among whom $10 / 25(40.0 \%)$ belonged to group with a score of $1-3$ and 15/25 (60.0\%) belonged to a group with a score of 4 - 6 (Table 1). Majority had the median modified Alvarado score of 7 with an interquartile range (IQR) of 7 - 8.

Among those with modified Alvarado score of $\geq 7,100.0 \%$ of them underwent appendicectomy and among those with $<7$, only $2 / 258.0 \%$ underwent appendicectomy (Table 2).

Combined HPR and USG were significantly associated with modified Alvarado scoring $(\mathrm{p}<0.05)$. After evaluating Alvarado score of $\geq 7$ with HPE reports the sensitivity, specificity, positive predictive value and negative predictive value were $97.4 \%, 79.3 \%, 92.7 \%$ and $92.0 \%$ respectively. Diagnostic accuracy was found to be $92.5 \%$. Among the patients with modified Alvarado score of $\geq 7$ (82) patients, 76 (92.7\%) patients were histopathologically positive, 6 patients were having normal appendix, hence negative appendicectomy rate was 7.3\% (Table 3) (Graph 1).

\begin{tabular}{|c|c|}
\hline \multicolumn{2}{|c|}{ Characteristics of the Study Participants } \\
\hline Age in Years (Mean \pm SD) & $26.54 \pm 10.46$ \\
\hline \multicolumn{2}{|l|}{ Gender (\%) } \\
\hline Males & 67.3 \\
\hline Females & 32.7 \\
\hline \multicolumn{2}{|l|}{ Complaints (\%) } \\
\hline Nausea/ Vomiting & 86.7 \\
\hline Anorexia & 61.9 \\
\hline Migration of pain & 46.3 \\
\hline \multicolumn{2}{|c|}{ Examination Findings and Investigations (\%) } \\
\hline Elevated Temperature & 80.0 \\
\hline RIF tenderness & 95.2 \\
\hline Rebound tenderness & 79.0 \\
\hline Leucocytosis & 49.5 \\
\hline \multicolumn{2}{|c|}{ Modified Alvarado Scoring (\%) } \\
\hline$\geq 7$ & 76.6 \\
\hline$<7$ & 23.4 \\
\hline
\end{tabular}




\begin{tabular}{|c|c|c|c|}
\hline \multirow{2}{*}{$\begin{array}{c}\text { Undergone } \\
\text { Appendicectomy }\end{array}$} & \multicolumn{2}{|c|}{ Modified Alvarado Scoring } & \multirow{2}{*}{$\begin{array}{l}\text { Total } \\
\text { n (\%) }\end{array}$} \\
\hline & $\geq 7$ n (\%) & <7 n (\%) & \\
\hline Yes & $82(100.0)$ & $2(8.0)$ & $84(78.5)$ \\
\hline No & $00(0.0)$ & $23(92.0)$ & $23(21.5)$ \\
\hline Total & $82(100.0)$ & $25(100.0)$ & $107(100.0)$ \\
\hline
\end{tabular}

\begin{tabular}{|c|c|c|c|c|}
\hline \multirow{2}{*}{$\begin{array}{c}\text { Modified } \\
\text { Alvarado } \\
\text { Scoring }\end{array}$} & \multicolumn{2}{|c|}{$\begin{array}{c}\text { Pre-op USG and/or HPE } \\
\text { Report }\end{array}$} & \multirow[t]{2}{*}{ Total } & \multirow{2}{*}{$\begin{array}{c}(\mathrm{P}- \\
\text { value) }\end{array}$} \\
\hline & Positive & Negative & & \\
\hline$\geq 7$ & $\begin{array}{c}76 \text { (True } \\
\text { positives) (a) }\end{array}$ & $\begin{array}{c}06 \text { (False } \\
\text { Positive) (b) }\end{array}$ & 82 & \multirow{3}{*}{$(<0.05)^{*}$} \\
\hline$<7$ & $\begin{array}{c}02 \text { (False } \\
\text { Negative) (c) }\end{array}$ & $\begin{array}{c}23 \text { (True } \\
\text { Negative) (d) } \\
\end{array}$ & 25 & \\
\hline Total & $78(a+c)$ & $29(b+d)$ & 107 & \\
\hline
\end{tabular}

Table 3. Sensitivity, Specificity, PPV and NPV of Modified Alvarado Scoring on Correlation with Pre-op USG and/or HPE Confirmation

*Indicates statistical significance at $\mathrm{p}<0.05$.

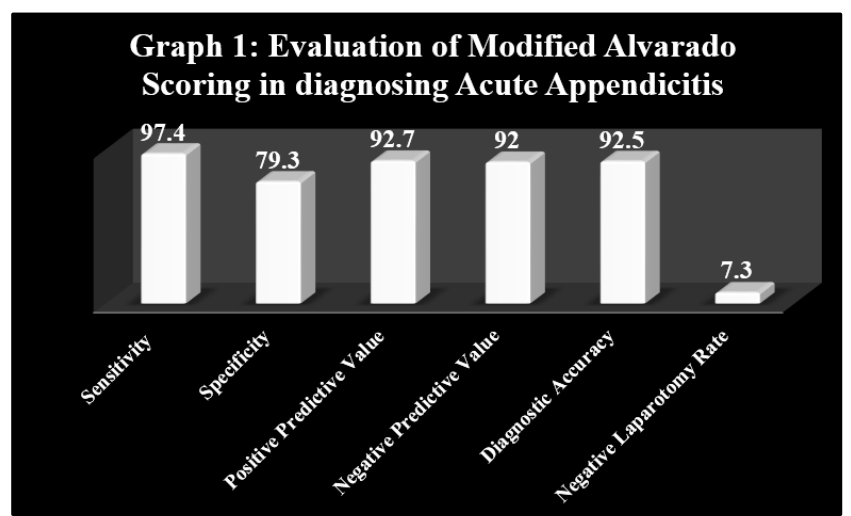

\section{DISCUSSION}

Acute appendicitis being one of the acute emergencies, many diagnostic techniques have been recommended, viz. clinical scoring systems, USG, CT scans, MRI and laparoscopy to identify the condition with an adequate accuracy to avoid the negative laparotomies and prevent the complications of delayed diagnosis like appendiceal perforation. USG is a cheap, quick and non-invasive diagnostic technique with an accuracy rate of $71 \%$ - $90 \%$ for diagnosis of acute appendicitis. Absolute and confirmed diagnosis is only possible at surgical exploration and histopathologic examination of the removed appendix. Modified Alvarado scoring systems is also one such technique to aid diagnosis. $3,13,14$

In the present study, a total of 107 patients were included and the age of the participants ranged from $2-65 \mathrm{yrs}$. with a mean of $26.54 \pm 10.46$ yrs. Similarly, Kanumba ES et al had included a total number of 127 patients in their study and the age of the participants ranged from 8 to 76 years (mean 29.64 \pm 12.97).15 Sabhnani G et al reported that majority of them with acute appendicitis were in the age group between 21 40 yrs., which is in parallel to the current study findings where majority were in 21 - 30 years' age group. ${ }^{16}$

Kumar SK et al has also included the participants ranging between 7 - 65 yrs. and males dominated the study which is similar to the current study findings. ${ }^{8}$

Gujar $\mathrm{N}$ et al reported majority of them having migration of pain to right iliac fossa as the commonest symptom, followed by nausea and vomiting and anorexia. ${ }^{2}$ However, in the current study, the commonest symptom was nausea and vomiting followed by anorexia and migration of pain to right iliac fossa. The slight difference may be due to varied presentation of appendicitis. Among the examination findings, majority (95.2\%) had right iliac fossa tenderness and it has been reported as $100.0 \%$ in other studies. ${ }^{2,17}$ Following right iliac fossa tenderness, majority had fever and rebound tenderness similar to the findings by Rithin PS et al. Leucocytosis was seen in $60.0 \%$ of the patients in our study and similarly it was found in $65.9 \%$ of the patients as noted by Rithin PS et al. ${ }^{17}$

Rithin PS et al noted that $79 \%$ of the patients had presented with a modified Alvarado score of $\geq 7$ and $21 \%$ presented with a score of $<7$. Similarly, in our study $76.6 \%$ belonged to a modified Alvarado score of $\geq 7$ and $23.4 \%$ belonged to $<7$. Median modified Alvarado scoring was 7 and is similar to findings by Kanumba ES et al. 15

Vandakudri $A B$ et al found 33 patients to be in the group score of $5-6,9$ were operated on clinical suspicion of high probability of acute appendicitis. Similarly, 25 were in the group score of $<7$ and 2 among those were operated for appendicectomy. ${ }^{18}$ The sensitivity, specificity, positive predictive value and negative predictive values of modified Alvarado scoring in the present study were $97.4 \%, 79.3 \%$, $92.7 \%$ and $92.0 \%$ respectively. Diagnostic accuracy was found to be $92.5 \%$. Similarly, Alamgir et al reported the finding of sensitivity (94.14\%), which is in agreement with the present study, but the finding of specificity was $66.66 \%$ which was lower than the finding of present study. 19 Raghavan SN et al documented nearly similar results with a sensitivity and specificity of $90.4 \%$ and $81.25 \%$ respectively. ${ }^{20}$ Singh SK et al reported the positive and negative predictive value for Modified Alvarado Score as $91.42 \%$ and $65 \%$ respectively and it has also noted a diagnostic accuracy of $81.82 \%$; however, the negative predictive value was higher in the present study. ${ }^{8}$ HPR and USG according to the modified Alvarado scores were significantly associated in the current study and is similar to the findings noted by Ramachandra $J$ et al. ${ }^{21}$ Negative appendicectomy rate in the present study was $7.3 \%$ and similarly Kodliwadamath HB et al has found similar rates $(7.6 \%)$ of negative laparotomies. ${ }^{10}$ However, the differences in diagnostic accuracy were observed, as the scores were applied to various populations and clinical settings. ${ }^{8}$

\section{Limitations}

The study needs to be conducted in larger samples to generalise the results. As the surgery was not conducted in all the study subjects, the calculation of sensitivity, specificity, positive predictive value, negative predictive value and diagnostic accuracy for modified Alvarado scoring was assessed on comparing with combined USG and HPE results.

\section{CONCLUSION}

Modified Alvarado score in the current study setting is found to have high sensitivity, positive predictive value, negative predictive value and overall diagnostic accuracy in diagnosing acute appendicitis. It also has good specificity in diagnosing acute appendicitis; hence, aids in fairly differentiating the conditions mimicking acute appendicitis. Negative laparotomy rate also being less it reduces 
misdiagnosis. Thus, we conclude that use of Modified Alvarado score in a low resource setting can be a very good tool to identify acute appendicitis early and prevent the progression of the disease and its complications.

\section{REFERENCES}

[1] Sammalkorpi HE, Mentula P, Leppäniemi A. A new adult appendicitis score improves diagnostic accuracy of acute appendicitis - a prospective study. BMC Gastroenterology 2014;14:114.

[2] Gujar N, Mudhol S, Choudhari RK, et al. Determination of sensitivity and specificity of modified alvarado score and ultrasonography in patients with acute appendicitis. JKIMSU 2015;4(2):89-99.

[3] Al-Dhahiry JKS, Melek HK, Abduljabbar TK, et al. Preoperative diagnosis of acute appendicitis: evaluation of modified Alvarado scoring system versus ultrasonography. JMSCR 2016;4(8):11862-9.

[4] Nautiyal H, Ahmad S, Keshwani NK, et al. Combined use of modified Alvarado score and USG in decreasing negative appendicectomy rate. Indian Journal of Surgery 2010;72(1):42-8.

[5] Chan I, Bicknell SG, Graham M. Utility and diagnostic accuracy of sonography in detecting appendicitis in a community hospital. AJR Am J Roentgenol 2005;184(6):1809-12.

[6] Samir M, Hefzy M, Gaber M, et al. Added value of graded compression ultrasound to the Alvarado score in cases of right iliac fossa pain. African Journal of Emergency Medicine 2016;6(3):138-43.

[7] Abdelrahim M, Khair R, Elsiddig K. The validity of Alvarado score in diagnosis of acute appendicitis among Sudanese patients. Surgery Curr Res 2016;6(1):257. doi:10.4172/2161- 1076.1000257

[8] Singh SK, Kunal, Chitrangada. Comparative study of diagnostic accuracy of modified Alvarado score and ultrasonography in acute appendicitis. IOSR-JDMS 2014;13(1):36-40.

[9] Kalan M, Talbot D, Cunliffe WJ, et al. Evaluation of the modified Alvarado score in the diagnosis of acute appendicitis: a prospective study. Ann R Coll Surg Engl 1994;76(6):418-9.

[10] Kodliwadamath HB, Bhaskaran A, Prasad CSBR, et al. Evaluation of modified Alvardo score in the diagnosis of acute appendicitis and its correlation with ultra sonography and histopathology. J Clin Biomed Sci 2011;1(4):149-57.
[11] Fenyo G, Lindberg G, Blind P, et al. Diagnostic decision support in suspected acute appendicitis: validation of a simplified scoring system. Eur J Surg Med 1997;163(11):831-8.

[12] Alvarado A. A practical score for the early diagnosis of acute appendicitis. Ann Emerg Med 1986;15(5):55764.

[13] Horzic M, Salamon A, Kopljar M, et al. Analysis of scores in diagnosis of acute appendicitis in women. Coll Anropol 2005;29(1):133-8.

[14] Ravindra J, Anjula J. A comparative study of diagnostic accuracy of clinical or other diagnostic modalities, used either alone or combined together in diagnosis of acute appendicitis in AVMC Jan 2013 - September 2014. Int J Biol Med Res 2015;6(2):4871-4.

[15] Kanumba ES, Mabula JB, Rambau P, et al. Modified Alvarado scoring system as a diagnostic tool for acute appendicitis at Bugando Medical Centre, Mwanza, Tanzania. BMC Surgery 2011;11:4.

[16] Sabhnani G, Tomar S. Negative laparotomy rates in acute abdomen: a declining trend. International Surgery Journal 2017;4(1):323-5.

[17] Rithin PS, Agarwal A, Budigi B. Evaluation of modified Alvarado scoring system in acute appendicitis at Vydehi Institute of Medical Sciences and Research Centre, Bangalore, Karnataka, India. International Surgery Journal 2017;4(7):2118-22.

[18] Vandakudri AB, Koppad SN, Gunasagar DM, et al. Evaluation of modified Alvarado score in the diagnosis of acute appendicitis. International Journal of Research in Medical Sciences 2016;4(1):84-8.

[19] Khan A, Munir A, Qadir S. Acute appendicitis: role of Alvarado scoring system in the diagnosis. Gomal Journal of Medical Sciences 2009;7(2)89-91.

[20] Raghavan SN, Raveendran S, Vamanaprabhu RR. Evaluation of modified Alvarado score in diagnosis of acute appendicitis- a prospective study comparing the score with histopathology. J Evolution Med Dent Sci 2017;6(29):2391-5.

[21] Ramachandra J, Sudhir M, Sathyanarayana BA. Evaluation of modified Alvarado score in preoperative diagnosis of acute appendicitis. Journal of Evolution of Medical and Dental Sciences 2013;2(46):9019-29. 